\title{
The Influence of Nanohydroxyapatite on the Thermal, Mechanical, and Tribological Properties of Polyoxymethylene Nanocomposites
}

\author{
Kinga Pielichowska, ${ }^{1}$ Dariusz Bieliński, ${ }^{2}$ Michał Dworak, ${ }^{1,3}$ Ewelina Kilian, ${ }^{1}$ \\ Beata Macherzyńska, ${ }^{1}$ and Stanisław Błażewicz ${ }^{1}$ \\ ${ }^{1}$ Department of Biomaterials, Faculty of Materials Science and Ceramics, AGH University of Science and Technology, \\ Al. Mickiewicza 30, 30-059 Kraków, Poland \\ ${ }^{2}$ Polymer Institute, Technical University of Lodz, ul. Zwirki 36, 90-924 Łódź, Poland \\ ${ }^{3}$ Institute of Materials Science, Faculty of Computer Science and Materials Science, University of Silesia, \\ ul. 75 Pułku Piechoty 1A, 41-500 Chorzów, Poland
}

Correspondence should be addressed to Kinga Pielichowska; kingapie@agh.edu.pl

Received 5 March 2017; Revised 25 April 2017; Accepted 15 May 2017; Published 15 June 2017

Academic Editor: Hossein Roghani-Mamaqani

Copyright (C) 2017 Kinga Pielichowska et al. This is an open access article distributed under the Creative Commons Attribution License, which permits unrestricted use, distribution, and reproduction in any medium, provided the original work is properly cited.

The influence of nanohydroxyapatite on the glass transition region and its activation energy, as well as on the tribological and mechanical properties of polyoxymethylene nanocomposites, was investigated using DMA, TOPEM DSC, nanoindentation, and nondestructive ultrasonic methods. It was found that the glass transition for unmodified POM was in the lower temperature range than in POM/HAp nanocomposites. Moreover, $\Delta C_{p}$ and activation energy were larger for POM/HAp nanocomposites. Friction coefficient was higher for POM/HAp nanocomposites in comparison to both POM homopolymer and POM copolymer. Simultaneously, the indentation test results show that microhardness is also higher for POM/HAp nanocomposites than for POM. From ultrasonic investigations it was found that the highest values of both longitudinal and transverse propagation waves and Young's and shear modulus for POM homopolymer (DH) and POM copolymer T2H and their nanocomposites can be attributed to their higher degree of crystallinity in comparison to UH copolymer. Moreover, for POM/HAp nanocomposites with 5\% of HAp, ultrasonic longitudinal wave velocity was almost constant even after 1000000 mechanical loading cycles, evidencing an enhancement of mechanical properties by HAp nanoparticles.

\section{Introduction}

Polyoxymethylene (POM) is one of the major thermoplastic engineering polymers and it is mainly applied in mechanical parts due to excellent performance against wear, high strength, stiffness, and excellent chemical resistance [13]. POM is also attractive material for use in biomedical applications such as bone tissue replacement especially in hip prosthesis [4], dentistry [5], and cardiology [6]. POM copolymer has been used for the spiked washer to reattach together with a bone screw ruptured ligaments to the bone. In the joint replacement applications, different POM implants like artificial finger and shoulder joints are well-known products [4]. In all these applications mechanical properties of POM are of crucial importance. POM exhibits good fatigue resistance, high impact strength, creep resistance, low friction, and good wear resistance due to its high degree of crystallinity and high bond energy [7]. As POM is a semicrystalline polymer with a relatively high degree of crystallinity, the bigger spherulites may act as the sites of stress concentration and, in consequence, the polymer has high notch sensitivity [8].

Various methods of improvement of POM mechanical properties have been proposed including incorporation of inorganic nanoparticles in the powder form. Hence, $\mathrm{Xu}$ et al. [9] found that the addition of reactable nano- $\mathrm{SiO}_{2}$ 
can enhance the tensile strength and Young's modulus of composites, and the impact strength of composites has a significant improvement at low contents of reactable nano$\mathrm{SiO}_{2}$, while, with the further increase of nanofiller content, the impact strength of composites shows a gradual decrease. Romero-Ibarra and coworkers [10] studied the influence of a radiopaque reinforcement-spherical barium sulphate $\left(\mathrm{BaSO}_{4}\right)$ in nanometric size, on the mechanical properties of POM. They observed that the introduction of 1 phr $\mathrm{BaSO}_{4}$ nanoparticles does not substantially modify the mechanical properties of the matrix, whereas upon increasing $\mathrm{BaSO}_{4}$ content to $3 \mathrm{phr}$ mechanical properties diminished.

$\mathrm{POM} / \mathrm{Al}_{2} \mathrm{O}_{3}$ nanocomposites were prepared by melt processing method and studied by Wacharawichanant et al. [11]. They revealed that the tensile strength and Young's modulus of the nanocomposites increased by adding $\mathrm{Al}_{2} \mathrm{O}_{3}$ particles in a range of $0.5-1$ wt.\% and then decreased. With increasing filler content, the impact strength of the nanocomposites decreased.

Wang et al. investigated [8] POM matrix composites with different contents of nano- $\mathrm{ZrO}_{2}$ particles and they found that the addition of $\mathrm{ZrO}_{2}$ nanoparticles can improve the tensile strength and impact strength by about $8 \%$ and $20 \%$, respectively, when the nano- $\mathrm{ZrO}_{2}$ content was $1.0 \mathrm{wt} . \%$ and the lowest wear appeared at 1.0 wt.\% content of $\mathrm{ZrO}_{2}$ nanoparticles.

To improve the bioactivity and biocompatibility of POM implants, Pielichowska et al. introduced to POM matrix hydroxyapatite (HAp, $\left.\left[\mathrm{Ca}_{10}\left(\mathrm{PO}_{4}\right)_{6}(\mathrm{OH})_{2}\right]\right)$, which is a wellknown bioceramics, chemically similar to human inorganic hard tissue $[12,13]$. Bone tissue is built from mineralized collagen (Col) fibrils, reinforced with 50-60 wt.\% of apatite crystals. HAp exhibits excellent biocompatibility, bioactivity, bone bonding properties, and osteoinduction, as shown by in vivo studies [14]. Due to the chemical similarity, HAp facilitates the formation of new bone without resorption and interacts with the living system [13]. On the other hand, incorporation of nanoparticles into POM matrix causes the effect of heterogeneous nucleation leading to thinner spherulites and lower degree of crystallinity, which can help to improve impact strength. The decrease of the crystallinity degree reduced the tensile strength $[8,15,16]$. We found in an in vitro evaluation that addition of HAp nanoparticles to POM matrix enhances bioactivity of the nanocomposites, and an excellent stability of POM/HAp nanomaterials under these conditions was confirmed [16].

Since for load bearing orthopaedic applications mechanical properties are of crucial importance, the aim of this study was to investigate in detail the influence of HAp nanoparticles on the tribological and mechanical (static and fatigue dynamic) properties of POM nanocomposites with hydroxyapatite. Please note that in our previous papers we investigated only tensile behaviour of POM/HAp nanocomposites [15-17]. In this study three POM types (homopolymer and two copolymers) with similar melt flow index and processability but with different mass-average molar mass have been used to find the best formulation for long-term orthopaedic implants.
TABLE 1: Description of the samples.

\begin{tabular}{lcc}
\hline POM & HAp content [wt.\%] & Sample code \\
\hline \multirow{3}{*}{ Delrin ${ }^{\circledR} 111 \mathrm{P}$} & 0.0 & $\mathrm{DH} 0$ \\
& 1.0 & $\mathrm{DH} 1$ \\
& 2.5 & $\mathrm{DH} 2.5$ \\
& 5.0 & $\mathrm{DH} 5$ \\
\hline Ultraform $^{\circledR} \mathrm{H} 2320004$ & 0.0 & $\mathrm{UH} 0$ \\
& 1.0 & $\mathrm{UH} 1$ \\
& 2.5 & $\mathrm{UH} 2.5$ \\
Tarnoform $^{\circledR} \mathrm{T} 200$ & 5.0 & $\mathrm{UH} 5$ \\
& 0.0 & $\mathrm{~T} 2 \mathrm{H} 0$ \\
& 1.0 & $\mathrm{~T} 2 \mathrm{H} 1$ \\
& 2.5 & $\mathrm{~T} 2 \mathrm{H} 2.5$ \\
& 5.0 & $\mathrm{~T} 2 \mathrm{H} 5$ \\
\hline
\end{tabular}

\section{Experimental Part}

2.1. Materials and Preparation. Three commercial grades of POM were investigated: POM homopolymer (Delrin ${ }^{\circledR} 111 \mathrm{P}$ ) (DH) with $M_{w}=96323 \mathrm{Da}$ was supplied by Du Pont; POM copolymer (Ultraform $\left.{ }^{\circledR} \mathrm{H} 2320004\right)(\mathrm{UH})$ with $M_{w}=78,565 \mathrm{Da}$ was obtained from BASF (Ludwigshafen, Germany), and POM T200 copolymer (Tarnoform $\left.{ }^{\circledR}\right)(\mathrm{T} 2 \mathrm{H})$ with $M_{w}=$ $100,768 \mathrm{Da}$ was produced by Z.A. Tarnów-Mościce. The melt flow index was 2.4, 2.6 and $2.5 \mathrm{~g} / 10 \mathrm{~min}$, respectively, according to MFR 190/2.16, ISO 1133. Hydroxyapatite $\mathrm{Ca}_{10}\left(\mathrm{PO}_{4}\right)_{6} \mathrm{OH}_{2}$ nanopowder (99\% of nanoparticle with size below $100 \mathrm{~nm}$ ) was supplied by nGimat Co. (Atlanta, USA). POM and POM/HAp nanocomposites were obtained using melt processing methods. Firstly, POM was dried, and then the POM and HAp were mechanically mixed $(0,0.5,1.0,2.5$, 5 , and $10.0 \% \mathrm{w} / \mathrm{w}$ of HAp) (Table 1 ), extruded in a twin-screw extruder ThermoHaake PolyLab PTW 16/25 (rotary speed of $50 \mathrm{rpm}$ ). Compositions were then shaped by using DSM laboratory injection molding machine. The proper dispersion of HAp nanoparticles in POM matrix was confirmed using TEM and SEM techniques. FTIR analysis results show that there is no chemical bonding between POM matrix and HAp nanoparticles, but HAp influenced POM crystallinity and mechanical properties [15-17].

\subsection{Techniques. For the DSC measurements DSC1 (Mettler} Toledo) operating in dynamic mode with heating rate of $10 \mathrm{~K} / \mathrm{min}$ and cooling rate of $10 \mathrm{~K} / \mathrm{min}$ was employed. Sample of ca. $6 \mathrm{mg}$ weight was placed in sealed and pierced aluminum pan. Nitrogen was used as an inert gas. For TOPEM DSC measurements the underlying heating rate was $0.5 \mathrm{~K} / \mathrm{min}$, the amplitude of the temperature pulse was $\pm 0.5 \mathrm{~K}$, and the switching time range to limit the duration of the pulses had the minimum of $15 \mathrm{~s}$ and the maximum of $50 \mathrm{~s}$. Sample of ca. $15 \mathrm{mg}$ weight was placed in sealed aluminum pans. Nitrogen with flow rate $30 \mathrm{~mL} / \mathrm{min}$ was used as the inert gas and the intracooler was used for cooling. DSC was calibrated using indium and mercury standards; an empty aluminum pan was used as a reference. 
Dynamic mechanical analysis was performed using a DMA 242C Netzsch in three-point bending mode $(20 \mathrm{~mm}$ sample holder) on bars with diameters of $10 \mathrm{~mm} \times 26 \mathrm{~mm}$, thickness $1 \mathrm{~mm}$ (obtained by injection molding method) in the temperature range within $-160-150^{\circ} \mathrm{C}$ in dry air. Measurements were performed at the heating rate of $2 \mathrm{deg} / \mathrm{min}$ and perturbation frequencies of $0,1,1,5$, and $10 \mathrm{~Hz}$, under maximal dynamic force of $6 \mathrm{~N}$, at constant part of static force of $0.3 \mathrm{~N}$ and static force $10 \%$ higher than dynamic one. The maximal amplitude was set to $50 \mu \mathrm{m}$. As a cooling medium liquid nitrogen was used.

The friction force of the stainless steel spherical tip of $r=$ $5 \mu \mathrm{m}$ sliding over the film surface was studied using a NanoTest 600 instrument (Micro Materials, UK), equipped with a friction attachment. Measurements were carried out at a normal load of $30 \mathrm{mN}$ and a sliding speed of $10 \mu \mathrm{m} / \mathrm{s}$ over a distance of $5 \mathrm{~mm}$, under ambient conditions. Coefficient of friction was calculated using well-known Amontons' formula-as an average value of friction force after stabilization of friction divided by the load.

Mechanical properties of the surface layer of polymers were determined using the NanoTest 600 instrument. A Berkovitch indenter penetrated the surface layer of polymers with the loading/unloading rate of $d P / d t=0.10 \mathrm{mN} / \mathrm{s}$, up to the maximum load of $P=5.00 \mathrm{mN}$. Mechanical parameters: hardness and elastic modulus were determined from unloading curves using the procedure of Oliver and Pharr [18]. The measurements were made at $T=20 \pm 2^{\circ} \mathrm{C}$ and relative humidity of $60 \pm 5 \%$. For each sample two series of seven measurements in various places on sample surface were performed and the data averaged.

Ultrasonic measurements were performed using the Ultrasonic Measuring System UZP-1 (INCO-VERITAS) with enhanced accuracy of the time of propagation of ultrasonic waves $( \pm 0.01 \mu \mathrm{s})$. An ultrasonic pulse technique was used to determine the elastic properties $(E, G$, and $\mu$ ). The $10 \mathrm{MHz}$ transducer with a diameter of $10 \mathrm{~mm}$ connected to a sample by paraffin oil was used for longitudinal waves, and the same transducer was glued with the samples by the Canadian balm for transverse waves. Material constants values were calculated using the following formula [19]:

$$
\begin{aligned}
G & =C_{T}^{2} * \rho, \\
E & =C_{L}^{2} \cdot \rho \cdot \frac{(1+\mu) \cdot(1-2 \mu)}{(1-\mu)}, \\
\mu & =\frac{C_{L}^{2}-2 C_{T}^{2}}{2\left(C_{L}^{2}-C_{T}^{2}\right)},
\end{aligned}
$$

where $E$ is ultrasonic Young's modulus, $G$ is Kirchhoff's modulus, $\mu$ is Poisson's Ratio, $\rho$ is apparent density, $C_{L}$ is speed of a longitudinal wave, and $C_{T}$ is speed of a transverse wave.

Mechanical dynamic loading was performed in the threepoint bending mode under a constant force amplitude using specimens with dimensions $40 \mathrm{~mm} \times 5 \mathrm{~mm} \times 2 \mathrm{~mm}$. The level of maximum force amplitude amounted to $50 \%$ of the sample strength determined in static mechanical test. After each 200000 cycles the samples were ultrasonically tested using Unipan-ultrasonic CT3 equipment with the $1 \mathrm{MHz}$ transducer and ultrasonic wave velocities were determined.

\section{Results and Discussion}

DMA results in the form of storage modulus $\left(E^{\prime}\right)$ and loss factor $(\tan \delta)$ as a function of temperature $(T)$ are demonstrated in Figures 1 and 2.

Earlier studies on the relaxation effects in pristine POM revealed three kinds of relaxations $-\alpha, \beta$, and $\gamma$. The first one recorded at ca. $-70^{\circ} \mathrm{C}$ as a broad peak was assigned to the glass to rubber $\gamma$ transition because of its "cooperative character" [20]. The other two peaks, observed at ca. -10 and $100^{\circ} \mathrm{C}$, correspond to $\beta$ and $\alpha$ relaxations, respectively. $\beta$ relaxation was assigned to the motions of long molecular segments in disordered phase [21], while $\alpha$ relaxation to movement of well-ordered crystalline phases. As it can be seen in Figures 1 and 2 also $\gamma$-mode at ca. $-74^{\circ} \mathrm{C}, \beta$-mode at $-10^{\circ}$, and $\alpha$ at $90^{\circ} \mathrm{C}$ can be observed for POM copolymers (UH and $\mathrm{T} 2 \mathrm{H}$ ) while for POM homopolymer (DH) just $\alpha$-mode at ca. $-73^{\circ} \mathrm{C}$ and $\alpha$ at ca. $100-110^{\circ} \mathrm{C}$ can be seen. Based on the frequency dependence of $\tan \delta$, glass transition at different frequencies was determined and from Arrhenius frequency map lnf versus $1000 / T_{g}$ (Figure 3 ) the activation energy of $\alpha$ mode was calculated. Moreover, to get a deeper insight into the glass transition region of investigated POM nanocomposites TOPEM DSC experiments were performed. Using conventional DSC it was impossible to determine $\gamma$-mode, but based on the reversing heat flow from TOPEM DSC one can detect $\gamma$ relaxation (Figure 4 ). Glass temperature, $\Delta C_{p}$ determined from TOPEM DSC, and activation energy $\left(E_{a}\right)$ data from DMA data $[22,23]$ are presented in Table 2.

As it can be seen from both TOPEM DSC and DMA results, the glass temperature for unmodified POM was lower than $T_{g}$ of POM/HAp nanocomposites. Moreover, $\Delta C_{p}$ and $E_{a}$ were larger for POM/HAp nanocomposites. A similar trend was observed by other authors for different polymer nanocomposites. Hence, Wong et al. [24] reported the linear increase in the glass transition temperature of poly(methyl methacrylate)/ZnO nanocomposites versus $\mathrm{ZnO}$ quantum dots weight content. It was assumed that the confinement effect between nanoparticles affects $T_{g}$ as a polymer thin film is sandwiched between two substrates $[25,26]$. Ceramic nanofillers such as HAp do not directly contribute to the $T_{g}$ value of the polymer matrix, but the interaction of the polymer chains with the surface of the particles can drastically alter the chain kinetics and mobility in the region surrounding the particle due to the presence of the interface. Due to the large surface area of nanofillers, for a welldispersed system, even low filler volume fractions provide a substantial amount of interfacial area through which the bulk properties of the polymer can be altered [27]. Rittigstein et al. [25] found that, in nanocomposites with well-dispersed nanofiller, $T_{g}$ can exhibit substantial deviations in relation to the bulk polymer, decreasing when polymer-nanofiller interfaces yield free surfaces [27, 28] and increasing when wetted interfaces with attractive interactions are present. When interactions, such as hydrogen bonds, are present 

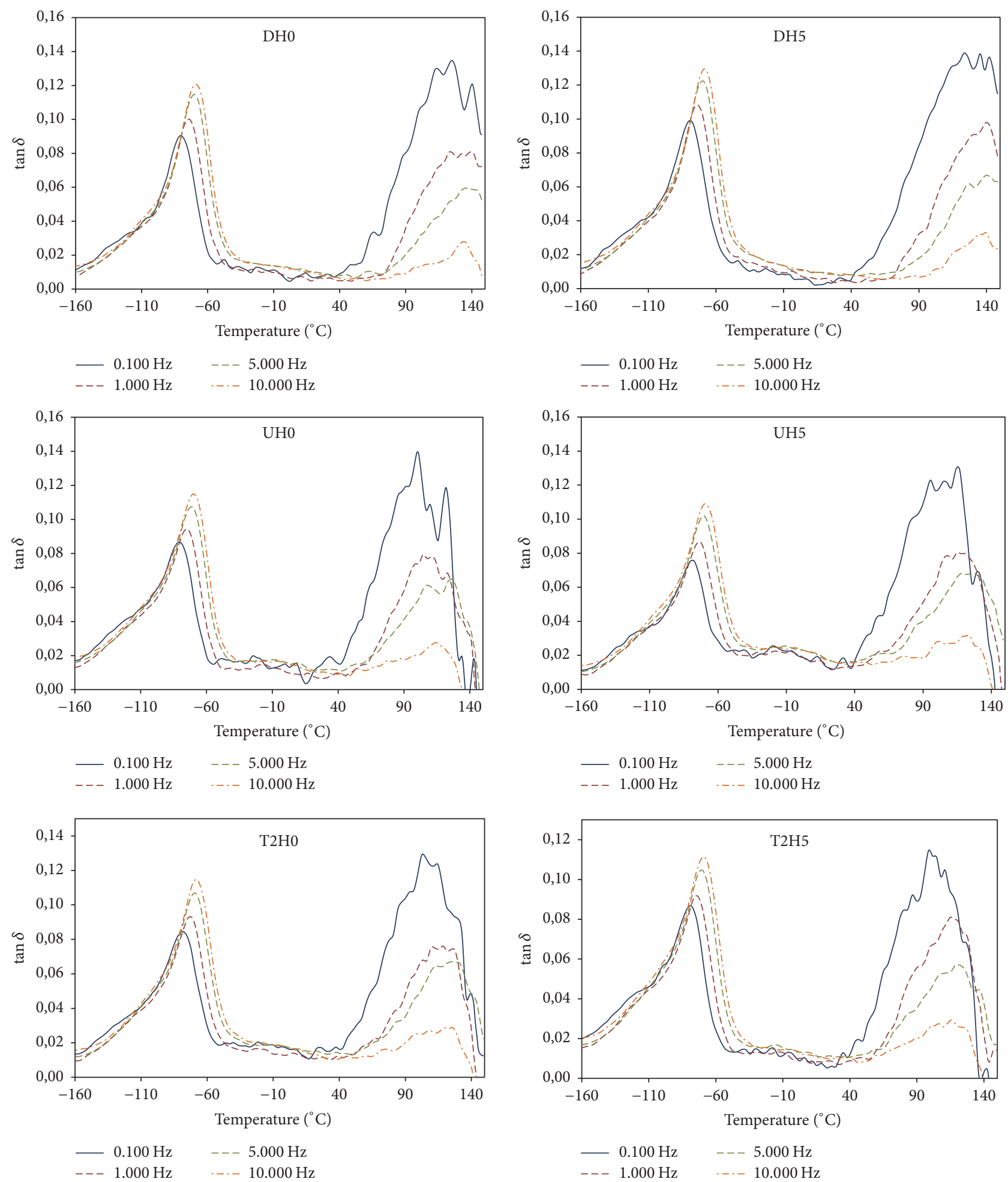

FIgURE 1: DMA curves for POM and POM/5\% HAp nanocomposites: $\tan \delta$ versus temperature.

at a polymer-substrate interface, confinement effects can lead to enhancements relative to bulk polymer properties [28]. The effects of confinement on $T_{g}$ in polystyrene (PS), poly(methyl methacrylate) (PMMA), and poly(2-vinyl pyridine) (P2VP) nanocomposites containing silica and alumina nanospheres were investigated, too [28]. In the aluminacontaining nanocomposites, $T_{g}$ increases relative to $T_{g \text {, bulk }}$ by as much as $16 \mathrm{~K}$ in $\mathrm{P} 2 \mathrm{VP}$, decreases by $5 \mathrm{~K}$ in PMMA, and is invariant in PS. These results were explained by wetted P2VPnanofiller interfaces with attractive interactions, nonwetted 
TABLE 2: Glass temperature, $\Delta C_{p}$, and activation energy of glass transition for POM and POM/HAp nanocomposites.

\begin{tabular}{lcccc}
\hline Sample & $T_{g}\left[{ }^{\circ} \mathrm{C}\right]$ (TOPEM DSC) by reversing heat flow & $\Delta C_{p}[\mathrm{~J} / \mathrm{molK}](\mathrm{TOPEM} \mathrm{DSC})$ & $T_{g}\left[{ }^{\circ} \mathrm{C}\right](\mathrm{DMA} 1 \mathrm{~Hz})$ & $E_{a}[\mathrm{~kJ} / \mathrm{mol}]$ \\
\hline DH0 & -74.5 & 0.070 & -74.3 & -73.7 \\
DH5 & -71.3 & 0.076 & -74.7 & 128.23 \\
UH0 & -77.0 & 0.052 & -73.9 & 134.48 \\
UH5 & -73.1 & 0.108 & -74.4 & 160.60 \\
T2H0 & -76.7 & 0.049 & -73.4 & 140.91 \\
T2H5 & -67.0 & 0.066 & 148.58 \\
\hline
\end{tabular}
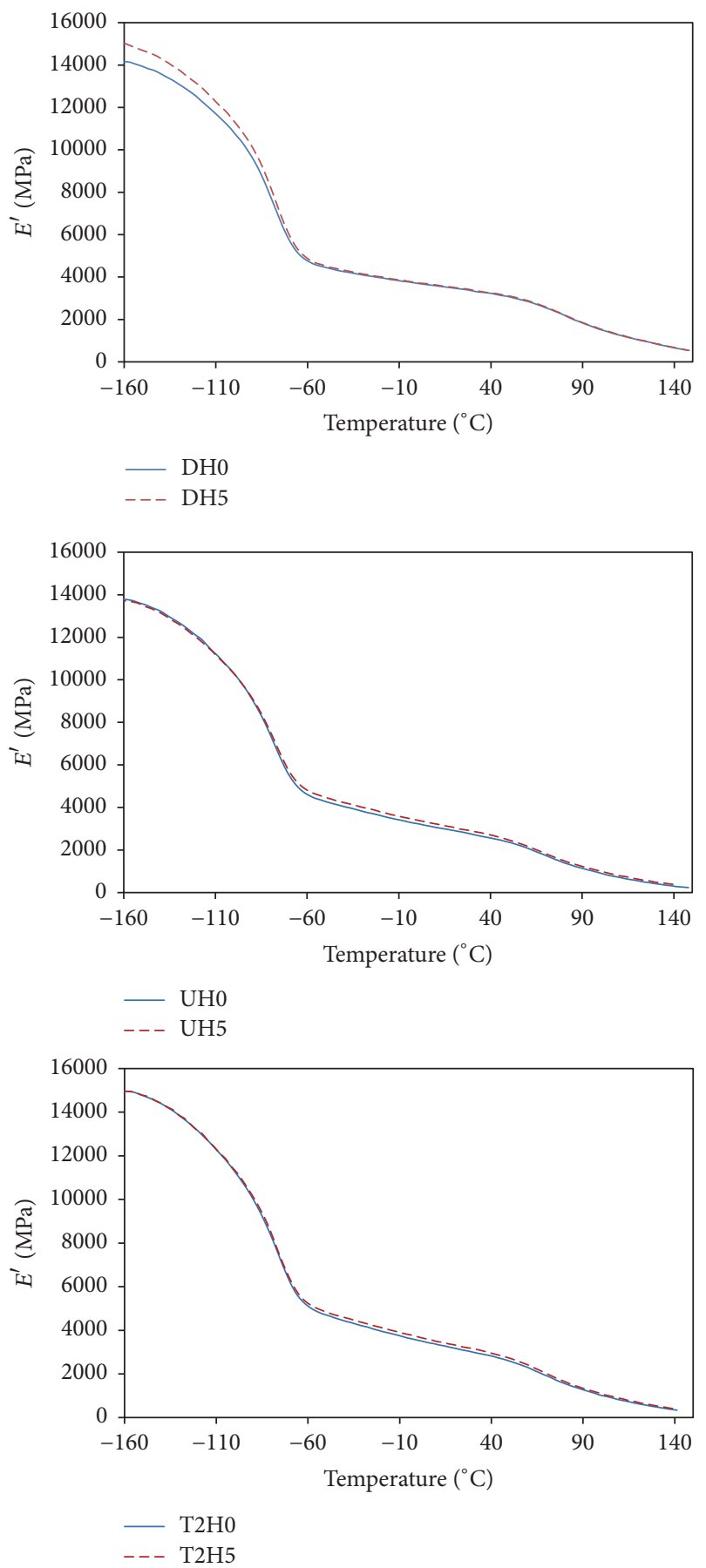

FIgURE 2: DMA curves for POM and POM/5\% HAp nanocomposites: $E^{\prime}$ versus temperature.

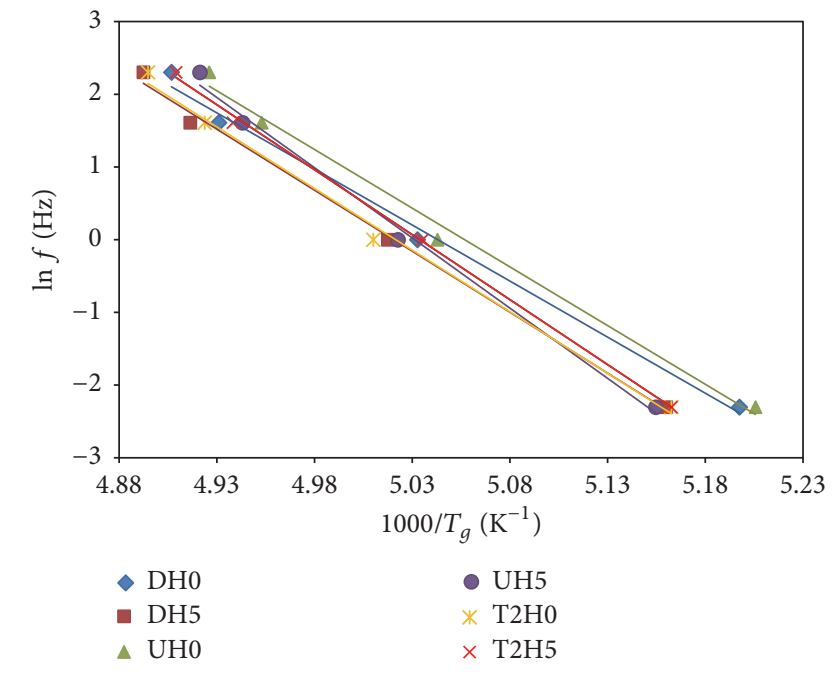

FIGURE 3: Arrhenius frequency map of POM and POM/HAp nanocomposites calculated from DMA results. DMA points correspond to the $\gamma$ peak at $\tan \delta$.

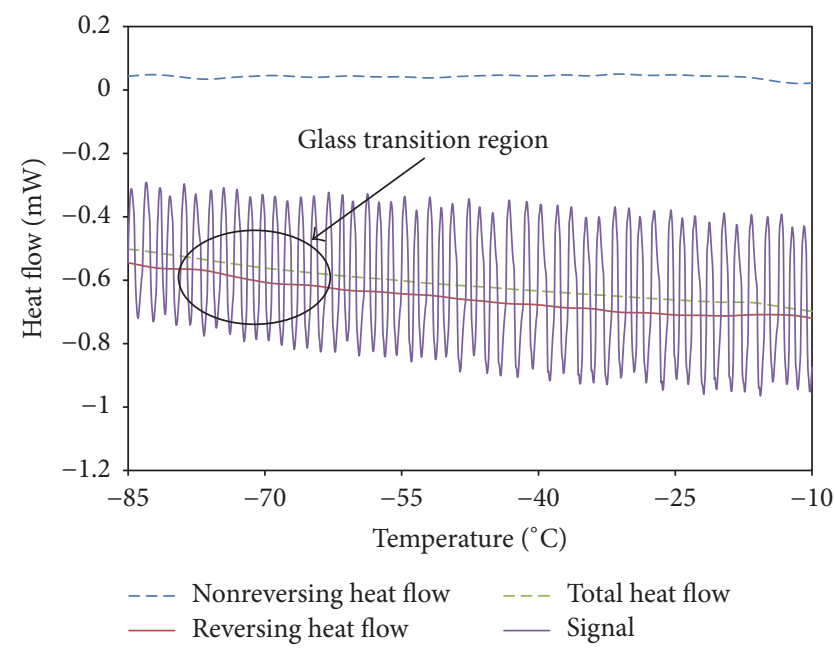

Figure 4: TOPEM DSC curves for DH0.

PMMA-nanofiller interfaces (free space at the interface), and wetted PS-nanofiller interfaces lacking attractive interactions, respectively. Additionally, the molecular dynamics simulations endorsed the hypothesis that $T_{g}$ of polymer nanocomposites can be enhanced or depressed by tuning the polymer-nanofiller interactions [27-30]. For POM/HAp 


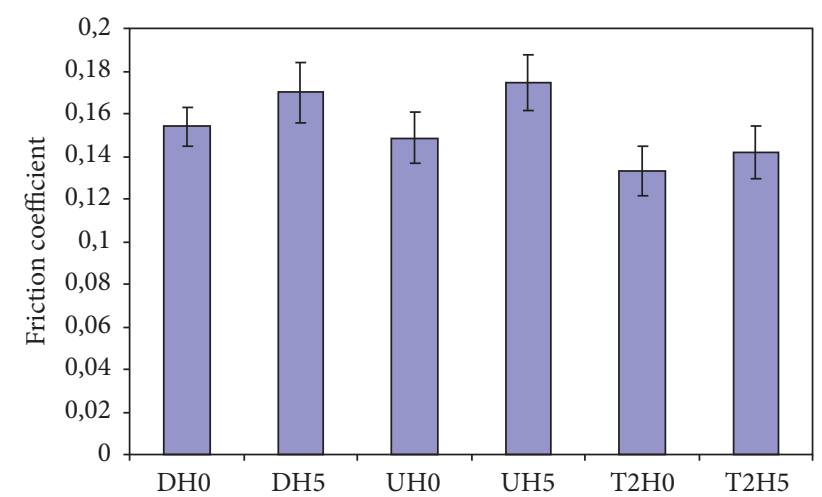

Figure 5: Friction coefficient for POM and POM/HAp nanocomposites.

nanocomposites, an increase in the glass temperature can be attributed to the interactions between HAp nanoparticles that contain polar groups- $\mathrm{OH}^{-}$and $\mathrm{PO}_{4}{ }^{3-}$ - and polymer chain with hydroxyl groups, as well as ether oxygen and acetic functionalities. The chemical structure of the components enables hydrogen bond formation between POM chains and HAp nanoparticles causing an increase of the glass temperature in POM/HAp nanocomposites. The increased activation energy of glass transition can be attributed to the confinement effects of polymer chains between HAp nanoparticles, leading to restricted chains mobility. Moreover, it can be observed that the lowest activation energy was found for POM homopolymer and higher for POM copolymers probably due to differences in macromolecular dynamics of POM chain between POM homo- and copolymer [31], while the glass temperature determined from DMA results was almost the same for all POM types.

In the next step, microtribological investigations were performed. Friction coefficient values of POM and POM/ HAp nanocomposites are presented in Figure 5.

Generally, the friction coefficient is higher for POM/HAp nanocomposites in comparison to pure POM, both homopolymer and copolymer. POM resin has been widely used as a self-lubricating material in numerous fields, such as automobile, electronic appliances, and machine engineering, because it exhibits good fatigue and creep resistance and high impact strength. POM low friction coefficient is attributed to the flexibility of the linear molecular chains, and simultaneously its good wear resistance is connected with its high crystallinity and high bond energy $[7,32]$. The influence of nanoadditives on the tribological properties depends on the kind of nanofiller. Sun et al. [7] investigated POM/3\% $\mathrm{Al}_{2} \mathrm{O}_{3}$ nanocomposite and POM nanocomposites with polytetrafluoroethylene (PTFE), molybdenum disulfide, and $\mathrm{Al}_{2} \mathrm{O}_{3}$ (POM/PTFE/MoS $/ 3 \% \quad \mathrm{Al}_{2} \mathrm{O}_{3}$ ) nanocomposite and reported that, under dry sliding conditions, $\mathrm{POM} / 3 \% \mathrm{Al}_{2} \mathrm{O}_{3}$ nanocomposite has higher friction coefficient and wear volume than neat $\mathrm{POM}$, while the friction coefficient and wear volume of $\mathrm{POM} / \mathrm{PTFE} / \mathrm{MoS}_{2} / 3 \% \mathrm{Al}_{2} \mathrm{O}_{3}$ nanocomposite decreased compared to neat POM. They suggested that, for $\mathrm{POM} / 3 \% \quad \mathrm{Al}_{2} \mathrm{O}_{3}$ nanocomposite, the peeling off and agglomeration of nanoparticles lead to a longer running-in

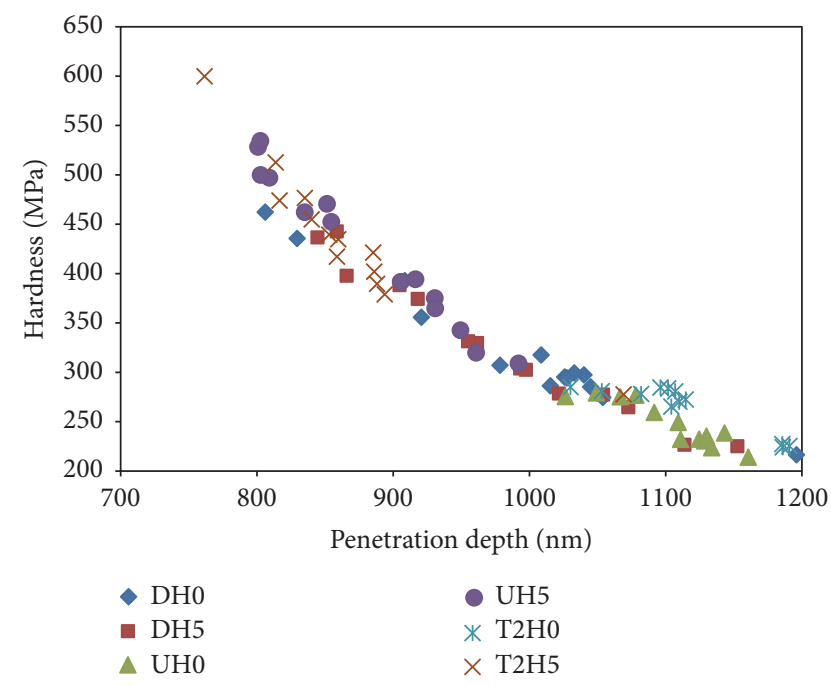

FIgURE 6: Hardness versus penetration depth for POM and POM/HAp nanocomposites.

period and also a higher friction coefficient. In contrast, for $\mathrm{POM} / \mathrm{PTFE} / \mathrm{MoS}_{2} / 3 \% \mathrm{Al}_{2} \mathrm{O}_{3}$ nanocomposite, nanoparticles can accelerate the formation of compact and uniform transfer films leading to a steady friction coefficient [7]. By analogy, in POM/HAp nanocomposites investigated in the course of this study, an increased friction coefficient was determined.

Results of nanoindentation investigations are presented in Figures 6 and 7.

All the materials studied exhibited the similar surface gradient of hardness. The indentation test results show that microhardness is generally higher for POM/HAp nanocomposites than for POM. Larger differences should be also noted in hardness of POM and POM/HAp nanocomposites for POM copolymer ( $\mathrm{UH}$ and $\mathrm{T} 2 \mathrm{H}$ ) whereby for POM homopolymer hardness increases only slightly. The highest hardness at the lowest penetration depth was measured for UH5 and T2H5 nanocomposites. The obtained results stay in good agreement with crystallinity level of the materials studied. For unmodified POM the highest degree of crystallinity was found for $\mathrm{DH} 0$, next one was for T2H0, and the lowest one was for UH0 (50.66\%, 49.26\%, and 45.17\%, resp.) while for POM HAp nanocomposites the highest degree of crystallinity was determined for T2H5, next one was for UH5, and the lowest one was for DH5 (52.94\%, 46.98\%, and 41.18\%, resp.) [15-17]. The same trend was observed for the hardness results that confirm our previous results. Different hardness values (Figure 6) can be probably attributed to crystalline and amorphous regions as shown in SEM microphotographs [1517]. This dependence was well documented in the literature for different macromolecular systems, and, generally, microhardness increases with increasing degree of crystallinity of polymer [33]. It was postulated that for polymers with crystallinity around 35\% containing nanocrystals randomly distributed within the amorphous phase a network of physical crosslinks connected by bridging molecules is formed. It induces a significant reinforcement of the material that leads 

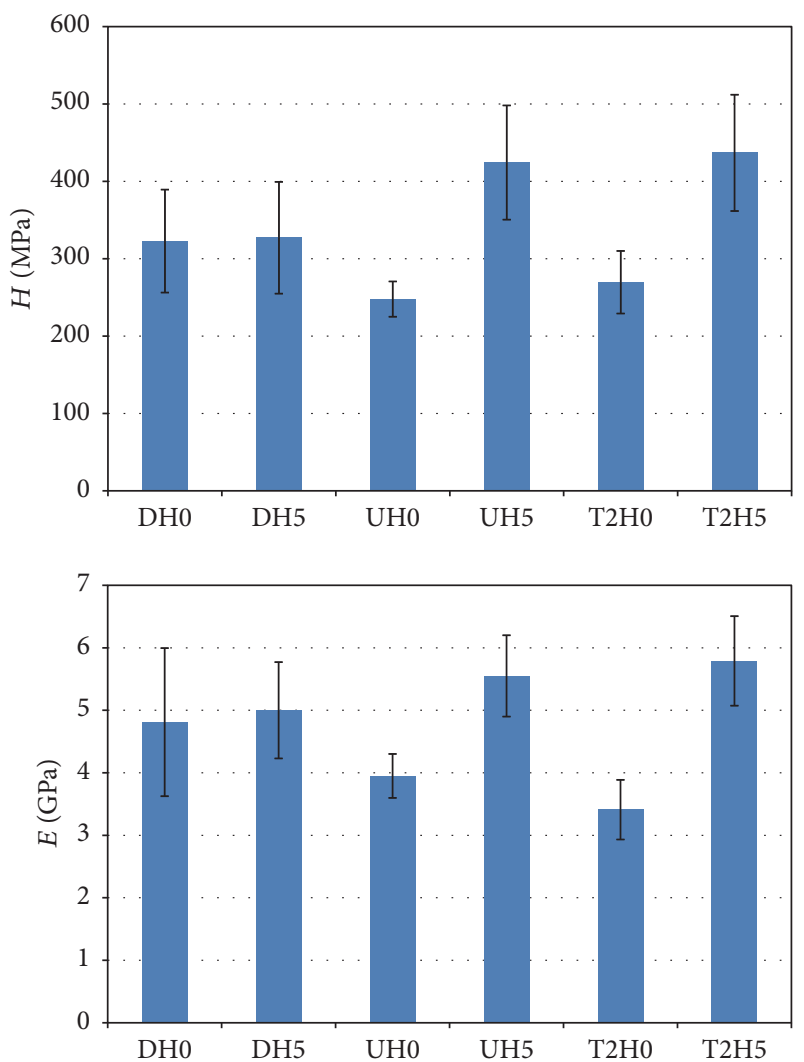

FIgure 7: Hardness and elastic modulus of POM and POM nanocomposites.

to an increase of microhardness, and the higher the amount of crystals the larger the reinforcing effect [33].

A similar trend is observed for elasticity modulus-higher values of modulus were found for POM/HAp nanocomposites. Similar effects were observed by Shen et al. [34] for polyamide 66/organoclay nanocomposites. These authors additionally postulated that the mechanical properties observed are correlated with the inhomogeneous microstructures of the systems under investigation.

Because of the application of POM/HAp nanocomposites in the field of bone implants, determination of their mechanical properties is of primary importance. Ultrasonic nondestructive testing method is a useful tool for characterization of nanocomposites homogeneity and elasticity. At first, the propagation velocity of longitudinal $C_{L}$ and transverse waves $\left(C_{T}\right)$ was determined-Figure 8.

The highest propagation velocities of both longitudinal and transverse ultrasonic waves can be observed for POM homopolymer (DH) and POM copolymer T2H and their nanocomposites. This effect can be attributed to the higher degree of crystallinity of $\mathrm{DH}$ and $\mathrm{T} 2 \mathrm{H}$ as well as their nanocomposites when comparing to the degree of crystallinity of UH copolymer and its nanocomposites [1517]. The reason is that ordered crystalline fractions produce stronger intermolecular interactions, leading to increased mechanical properties and, consequently, to an increase of ultrasonic wave velocity [35]. Ultrasonic waves in polymeric materials can propagate through slight translocation of
TABle 3: Apparent density and Poisson ratio for POM and POM/HAp nanocomposites.

\begin{tabular}{lcc}
\hline Sample & $\rho\left[\mathrm{g} / \mathrm{cm}^{3}\right]$ & $\mu$ \\
\hline DH0 & 1.42 & 0.41 \\
DH1 & 1.40 & 0.41 \\
DH2.5 & 1.41 & 0.41 \\
DH5 & 1.36 & 0.40 \\
UH0 & 1.44 & 0.42 \\
UH1 & 1.39 & 0.42 \\
UH2.5 & 1.34 & 0.41 \\
UH5 & 1.42 & 0.42 \\
T2H0 & 1.57 & 0.42 \\
T2H1 & 1.51 & 0.42 \\
T2H2.5 & 1.45 & 0.40 \\
T2H5 & 1.52 & 0.40 \\
\hline
\end{tabular}

atoms, groups, and chain segments around their equilibrium positions. The forces operating along chain segments and between macromolecular chains lead to translocations into neighbouring macromolecules, thus involving stress waves through the material $[19,36,37]$. Next, based on the measurements of ultrasonic wave velocity, the Poisson ratio was calculated-Table 3.

The Poisson ratio is in the range $0.40-0.42$ that is a value typical for semicrystalline polymers $[38,39]$ and is generally lower for POM/HAp nanocomposites with higher HAp loading. During semicrystalline polymer stretching firstly the onset of isolated inter- and intralamellar slip processes is observed after the initial Hooke elastic range, next it changes into a collective activity of slip motions of crystal blocks at the point of maximum curvature of the true stress-strain curve, and, finally, the beginning of destruction of crystal blocks followed by recrystallization with formation of fibrils occurs. It is accompanied by the beginning of disentanglement of the amorphous network or strain hardening due to the stretching of the amorphous entangled network at high deformations [40]. For polymer composites, the stress concentration causes around the filler particles the effect of external load, whereby the actual stress distribution decides about the extent of local micromechanical deformation processes [41]. In polymer composites the prevalent deformation mechanism is debonding on the matrix/filler interface that leads to some volume increase during deformation $[42,43]$. For POM/HAp nanocomposites we found in our previous study [15] that the strain-stress curves have very clear yielding points showing ductile characteristics, but, with an increase of HAp content, the ductile properties decrease and the materials become brittle. This also proves the excellent fillermatrix adhesion of POM/HAp nanocomposites-the better the adhesion between nanoparticles and polymer matrix, the more difficult the movement of macrochains that restricts deformation during tensile stress and leads to a decrease of Poisson ratio. It is noteworthy that for unmodified POM these restrictions are not present. For POM/HAp nanocomposites with lower HAp loading the restrictions in the chain mobility are too low to change the Poisson ratio. 


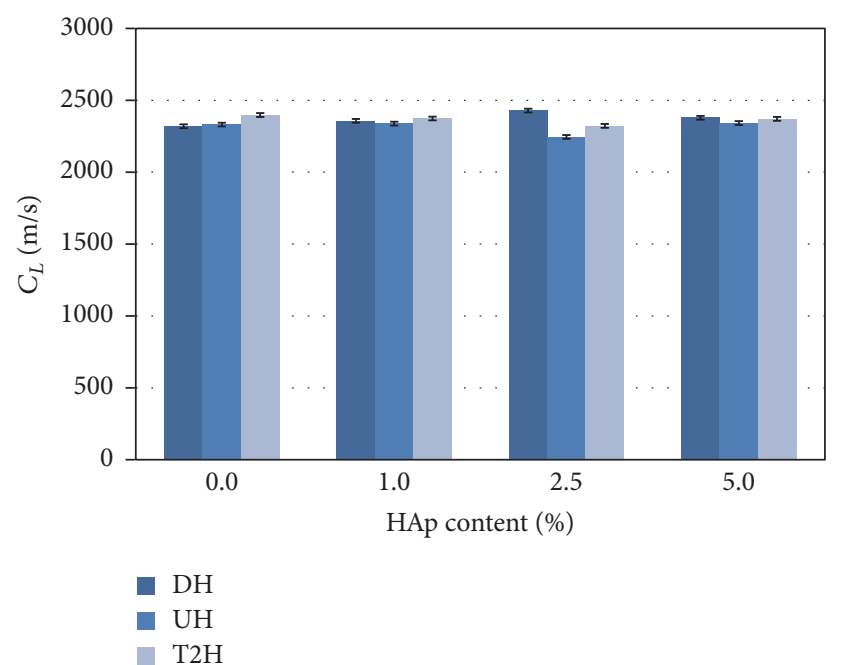

(a)

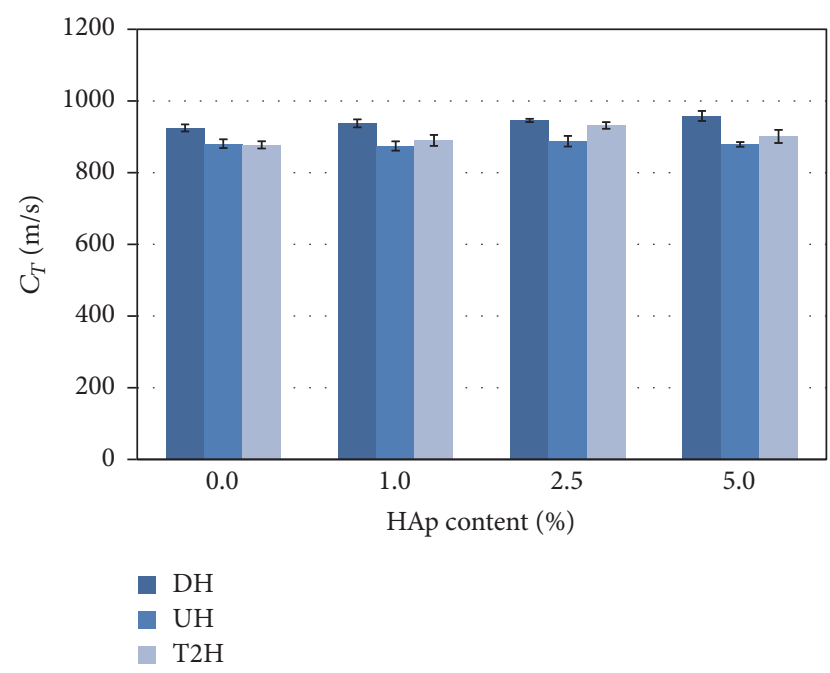

(b)

FIGURE 8: Longitudinal wave velocity $\left(C_{L}\right)$ (a) and transverse wave velocity $\left(C_{T}\right)(\mathrm{b})$ of POM and POM/HAp nanocomposites with different HAp content.

Based on these results, ultrasonic Young's modulus $E$ [GPa] and Kirchhoff's modulus $G$ [GPa] were calculatedFigure 9.

It can be seen that the elastic properties strongly depend on the HAp concentration and type of POM and their crystallinity. The highest values of Young's and shear moduli were found for polymers with the highest degree of crystallinity-higher moduli were obtained for $\mathrm{DH}$ and $\mathrm{T} 2 \mathrm{H}$ systems in comparison to UH copolymer. To check the mechanical properties stability, the samples were tested up to $10^{6}$ cycles under dynamical loading. Results of measurements of longitudinal ultrasonic wave velocity after these tests are presented in Figure 10.

Larger changes in ultrasonic longitudinal wave velocity were detected for unmodified POM while for POM/HAp nanocomposites with $5 \%$ of HAp longitudinal wave velocity was almost constant even after $10^{6}$ cycles, proving an enhancement of the mechanical properties stability by HAp nanoparticles. This effect can probably be attributed to the restriction of POM chain mobility due to the presence of HAp nanoparticles and their nucleating effect on POM chains that leads to the formation of larger amounts of smaller and more defected spherulites.

\section{Conclusions}

In this work, the influence of nanohydroxyapatite on the glass transition region and its activation energy and tribological and mechanical properties of polyoxymethylene nanocomposites was investigated. It was found that glass transition for unmodified POM was in the lower temperature range than for POM/HAp nanocomposites. Moreover, $\Delta C_{p}$ and activation energy were larger for POM/HAp nanocomposites which can be attributed to confinement effect of polymer chains between HAp nanoparticles which restricted chains mobility. The lowest activation energy was found
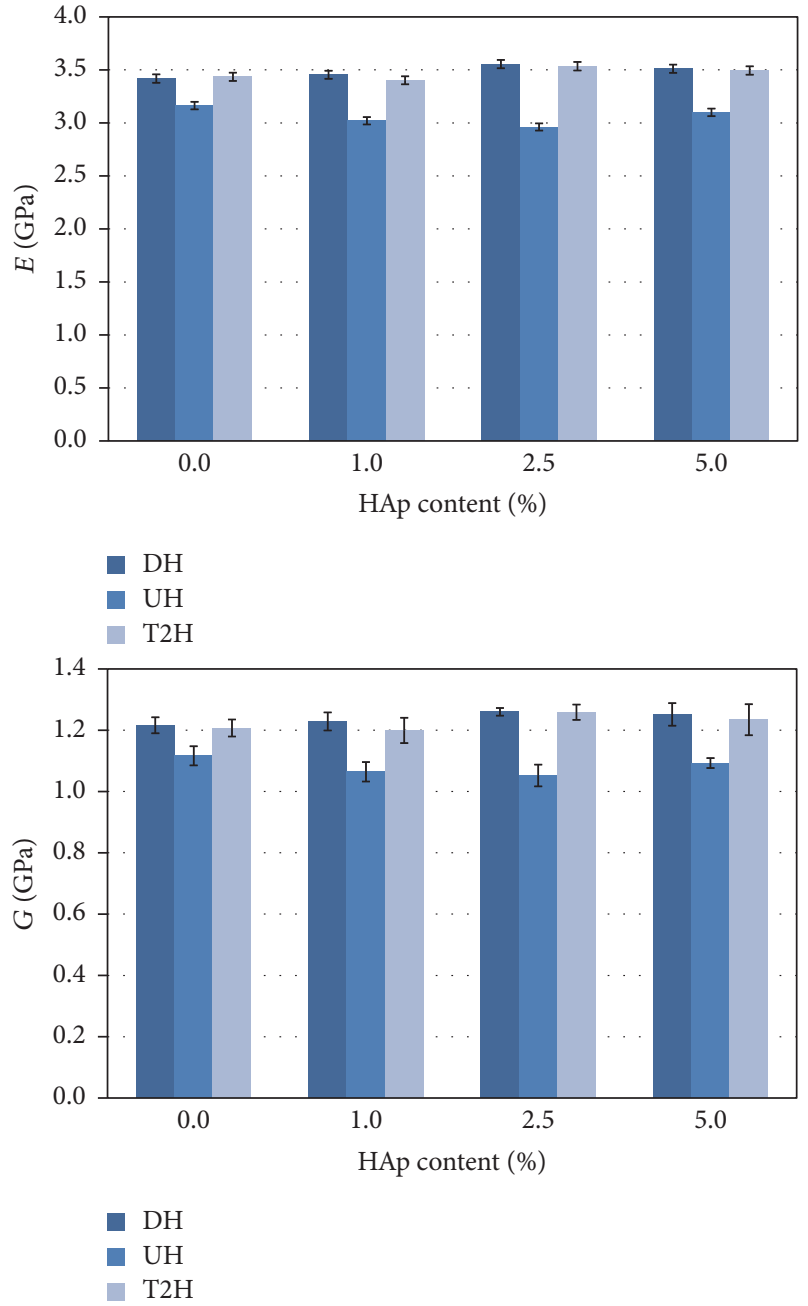

FIGURE 9: Ultrasonic Young's modulus $E[\mathrm{GPa}]$ and Kirchhoff's modulus $G$ [GPa] calculated based on measurements of ultrasound velocities. Error bars represent standard deviation. 

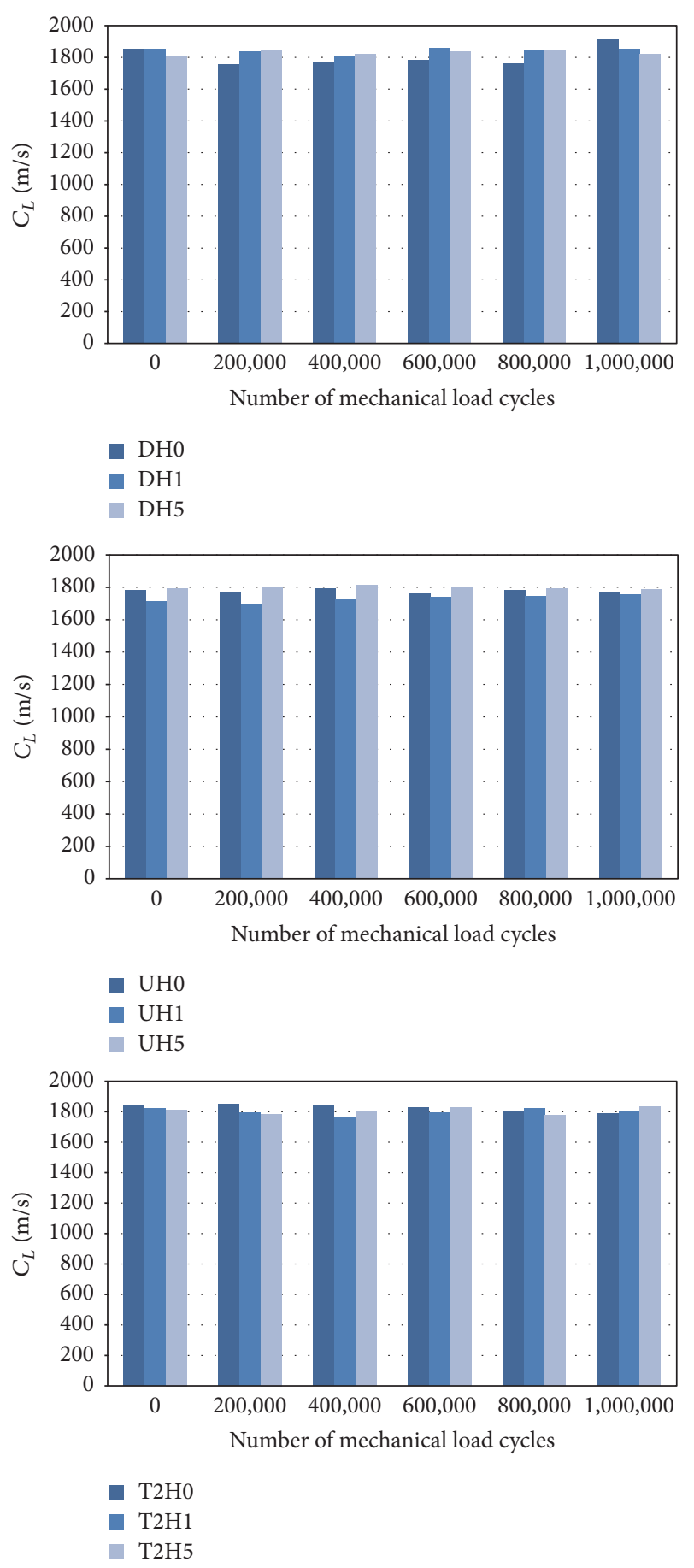

Figure 10: Longitudinal wave velocity $\left(C_{L}\right)$ for POM and POM/HAp nanocomposites after dynamical loading.

for DH homopolymer, while the highest activation energy for UH5 nanocomposite. Friction coefficient was higher for POM/HAp nanocomposites in comparison to pure POM both homopolymer and copolymer, but it also should be noted that higher values were observed for DH. Simultaneously, the indentation test results show that microhardness is also higher for POM/HAp nanocomposites than for $\mathrm{POM}$, but more significant changes were observed for POM copolymers. Based on the literature data this effect can be explained by inhomogeneous distributions of the crystalline morphology as well as by HAp concentration changes along the indentation direction. From ultrasonic investigations the highest propagation velocity was found of both longitudinal and transverse ultrasonic waves and ultrasonic Young's and shear modulus for POM homopolymer (DH) and POM copolymer $\mathrm{T} 2 \mathrm{H}$ and their nanocomposites which can be attributed to their higher degree of crystallinity in comparison to $\mathrm{UH}$ copolymer. Poisson ratio was in the range $0.40-0.42$ and was generally lower for POM/HAp nanocomposites with higher HAp loading due to good adhesion between POM and HAp that hinders the movements of macrochains and restricts deformation under force. Besides, for POM/HAp nanocomposites with 5\% of HAp, ultrasonic longitudinal wave velocity was almost constant even after $10^{6}$ mechanical loading cycles proving an enhancement of mechanical properties stability by HAp nanoparticles. This probably can be attributed to the restriction of POM chain mobility due to the presence of HAp nanoparticles showing good adhesion with POM matrix, as well as their nucleating effect on the POM macrochains.

\section{Conflicts of Interest}

The authors declare that there are no conflicts of interest regarding the publication of this paper.

\section{Acknowledgments}

One of the authors (Kinga Pielichowska) is grateful to the Polish Ministry of Science and Higher Education for financial support under Grant no. PBZ/MEiN/01/2006/15. This work was partially financed by statute fund of Faculty of Materials Science and Ceramics AGH-UST under Contract no. 11.11.160.616.

\section{References}

[1] S. Wacharawichanant, S. Thongyai, A. Phutthaphan, and C. Eiamsam-ang, "Effect of particle sizes of zinc oxide on mechanical, thermal and morphological properties of polyoxymethylene/zinc oxide nanocomposites," Polymer Testing, vol. 27, no. 8, pp. 971-976, 2008.

[2] K. Takasa, N. Miyashita, and K. Takeda, "Young modulus and degree of crystallization of highly-elongated polyoxymethylene," Journal of Applied Polymer Science, vol. 101, no. 2, pp. 12231227, 2006.

[3] K. Pielichowska, "Polyacetals," in Handbook of Thermoplastics, O. Olabisi and K. Adewale, Eds., CRC Press, Boca Raton, Florida, USA, 2nd edition, 2015.

[4] L. Eschbach, "Nonresorbable polymers in bone surgery," Injury, vol. 31, supplement 4, pp. D22-D27, 2000.

[5] T. Eliades, "Orthodontic materials research and applications: Part 2. Current status and projected future developments in materials and biocompatibility," American Journal of Orthodontics and Dentofacial Orthopedics, vol. 131, no. 2, pp. 253-262, 2007. 
[6] SH. Teoh, "New insight into the fracture and wear problems of a mechanical heart valve - in vitro microstrain, creep rupture, and wear studies," in Heart Replacement, T. Akutsu and H. Koyanagi, Eds., pp. 348-352, Springer, Japan, 1998.

[7] L.-H. Sun, Z.-G. Yang, and X.-H. Li, "Mechanical and tribological properties of polyoxymethylene modified with nanoparticles and solid lubricants," Polymer Engineering and Science, vol. 48, no. 9, pp. 1824-1832, 2008.

[8] J. Wang, X. G. Hu, M. Tian, and R. Stengler, "Study on mechanical and tribological property of nanometer $\mathrm{ZrO} 2$-filled polyxymethylene composites," Polymer - Plastics Technology and Engineering, vol. 46, no. 5, pp. 469-473, 2007.

[9] X. Xu, L. Guo, Y. Zhang, and Z. Zhang, "Mechanical and thermal properties of reactable nano-SiO 2/polyoxymethylene composites," Advanced Materials Research, vol. 535-537, pp. 103109, 2012.

[10] I. C. Romero-Ibarra, E. Bonilla-Blancas, A. Sánchez-Solís, and O. Manero, "Influence of X-ray opaque $\mathrm{BaSO}_{4}$ nanoparticles on the mechanical, thermal and rheological properties of polyoxymethylene nanocomposites," Journal of Polymer Engineering, vol. 32, no. 4-5, pp. 319-326, 2012.

[11] S. Wacharawichanant, P. Sahapaibounkit, and U. Saeueng, "Study on Mechanical and Morphological Properties of Polyoxymethylene/ $\mathrm{Al}_{2} \mathrm{O}_{3}$ Nanocomposites," in Proceedings of the TIChE International Conference 2011, Songkhla, Thailand, 2011.

[12] E. Bouyer, F. Gitzhofer, and M. I. Boulos, "Morphological study of hydroxyapatite nanocrystal suspension," Journal of Materials Science: Materials in Medicine, vol. 11, no. 8, pp. 523-531, 2000.

[13] K. Pielichowska and S. Blazewicz, "Bioactive polymer/hydroxyapatite (nano)composites for bone tissue regeneration," Advances in Polymer Science, vol. 232, no. 1, pp. 97-207, 2010.

[14] R. K. Roeder, G. L. Converse, R. J. Kane, and W. Yue, "Hydroxyapatite-reinforced polymer biocomposites for synthetic bone substitutes," JOM, vol. 60, no. 3, pp. 38-45, 2008.

[15] K. Pielichowska, A. Szczygielska, and E. Spasówka, "Preparation and characterization of polyoxymethylene-copolymer/ hydroxyapatite nanocomposites for long-term bone implants," Polymers for Advanced Technologies, vol. 23, no. 8, pp. 1141-1150, 2012.

[16] K. Pielichowska, "Polyoxymethylene-homopolymer/hydroxyapatite nanocomposites for biomedical applications," Journal of Applied Polymer Science, vol. 123, no. 4, pp. 2234-2243, 2012.

[17] K. Pielichowska, "The influence of molecular weight on the properties of polyacetal/ hydroxyapatite nanocomposites. Part 1. Microstructural analysis and phase transition studies," Journal of Polymer Research, vol. 19, no. 2, article no. 9775, 2012.

[18] W. C. Oliver and G. M. Pharr, "Improved technique for determining hardness and elastic modulus using load and displacement sensing indentation experiments," Journal of Materials Research, vol. 7, no. 6, pp. 1564-1580, 1992.

[19] J. Krautkrämer and H. Krautkrämer, Introduction. ultrasonic testing of materials, Springer, Berlin, Heidelberg, 1990.

[20] G. C. Psarras, S. Siengchin, P. K. Karahaliou, S. N. Georga, C. A. Krontiras, and J. Karger-Kocsis, "Dielectric relaxation phenomena and dynamics in polyoxymethylene/polyurethane/alumina hybrid nanocomposites," Polymer International, vol. 60, no. 12, pp. 1715-1721, 2011.

[21] B. B. Sauer, P. Avakian, E. A. Flexman, M. Keatinc, B. S. Hsiao, and R. K. Verma, "A.C. Dielectric and TSC studies of constrained amorphous motions in flexible polymers including
poly(OxyMethylene) and miscible blends," Journal of Polymer Science, Part B: Polymer Physics, vol. 35, no. 13, pp. 2121-2132, 1997.

[22] G. Rotter and H. Ishida, "Dynamic mechanical analysis of the glass transition. Curve resolving applied to polymers," Macromolecules, vol. 25, no. 8, pp. 2170-2176, 1992.

[23] G. Li, P. Lee-Sullivan, and R. W. Thring, "Determination of activation energy for glass transition of an epoxy adhesive using dynamic mechanical analysis," Journal of Thermal Analysis and Calorimetry, vol. 60, no. 2, pp. 377-390, 2000.

[24] M. Wong, R. Tsuji, S. Nutt, and H.-J. Sue, "Glass transition temperature changes of melt-blended polymer nanocomposites containing finely dispersed $\mathrm{ZnO}$ quantum dots," Soft Matter, vol. 6, no. 18, pp. 4482-4490, 2010.

[25] P. Rittigstein, R. D. Priestley, L. J. Broadbelt, and J. M. Torkelson, "Model polymer nanocomposites provide an understanding of confinement effects in real nanocomposites," Nature Materials, vol. 6, no. 4, pp. 278-282, 2007.

[26] A. Bansal, H. Yang, C. Li et al., "Quantitative equivalence between polymer nanocomposites and thin polymer films," Nature Materials, vol. 4, no. 9, pp. 693-698, 2005.

[27] B. J. Ash, L. S. Schadler, and R. W. Siegel, "Glass transition behavior of alumina/polymethylmethacrylate nanocomposites," Materials Letters, vol. 55, no. 1-2, pp. 83-87, 2002.

[28] P. Rittigstein and J. M. Torkelson, "Polymer-nanoparticle interfacial interactions in polymer nanocomposites: Confinement effects on glass transition temperature and suppression of physical aging," Journal of Polymer Science, Part B: Polymer Physics, vol. 44, no. 20, pp. 2935-2943, 2006.

[29] J. Koszkul and D. Kwiatkowsk, "The creep tests of polyoxymethylene composites reinforced with the microspheres from fly ashes," Journal of Materials Processing Technology, vol. 157-158, pp. 360-363, 2004.

[30] Y. Sun, Z. Zhang, K.-S. Moon, and C. P. Wong, "Glass transition and relaxation behavior of epoxy nanocomposites," Journal of Polymer Science, Part B: Polymer Physics, vol. 42, no. 21, pp. 3849-3858, 2004.

[31] E. G. Merino, S. Atlas, M. Raihane et al., "Molecular dynamics of poly(ATRIF) homopolymer and poly(AN-co-ATRIF) copolymer investigated by dielectric relaxation spectroscopy," European Polymer Journal, vol. 47, no. 7, pp. 1429-1446, 2011.

[32] J. Chen, Y. Cao, and H. Li, "Investigation of the friction and wear behaviors of polyoxymethylene/linear low-density polyethylene/ethylene-acrylic-acid blends," Wear, vol. 260, no. 11-12, pp. 1342-1348, 2006.

[33] A. Flores, F. Ania, and F. J. Baltá-Calleja, "From the glassy state to ordered polymer structures: a microhardness study," Polymer, vol. 50, no. 3, pp. 729-746, 2009.

[34] L. Shen, I. Y. Phang, T. Liu, and K. Zeng, "Nanoindentation and morphological studies on nylon 66/organoclay nanocomposites. II. Effect of strain rate," Polymer, vol. 45, no. 24, pp. 82218229, 2004.

[35] F. Lionetto, F. Montagna, and A. Maffezzoli, "Ultrasonic dynamic mechanical analysis of polymers," Applied Rheology, vol. 15, no. 5, pp. 326-335, 2005.

[36] Committee ASMH. Metals Handbook: Nondestructive evaluation and quality control: American Society for Metals.

[37] F. Lionetto and A. Maffezzoli, "Polymer characterization by ultrasonic wave propagation," Advances in Polymer Technology, vol. 27, no. 2, pp. 63-73, 2008. 
[38] D. I. Bower, An Introduction to Polymer Physics, Cambridge University Press, 2002.

[39] G. N. Greaves, A. L. Greer, R. S. Lakes, and T. Rouxel, "Poisson's ratio and modern materials," Nature Materials, vol. 10, no. 11, pp. 823-837, 2011.

[40] C. De Rosa and F. Auriemma, "Stress-induced phase transitions in metallocene-made isotactic polypropylene," in Progress in Understanding of Polymer Crystallization. Lecture Notes in Physics. 714, G. Reiter and G. Strobl, Eds., pp. 345-371, Springer, Berlin Heidelberg, 2007.

[41] C. Bucknall, Toughened plastics. London: Applied Science Publishers, Ltd, 1977.

[42] B. Pukánszky, M. Van Es, F. H. J. Maurer, and G. Vörös, "Micromechanical deformations in particulate filled thermoplastics: volume strain measurements," Journal of Materials Science, vol. 29, no. 9, pp. 2350-2358, 1994.

[43] A. Sudar, J. Moczo, G. Voros, and B. Pukanszky, "The mechanism and kinetics of void formation and growth in particulate filled PE composites," eXPRESS Polymer Letters, vol. 1, pp. 763772, 2007. 

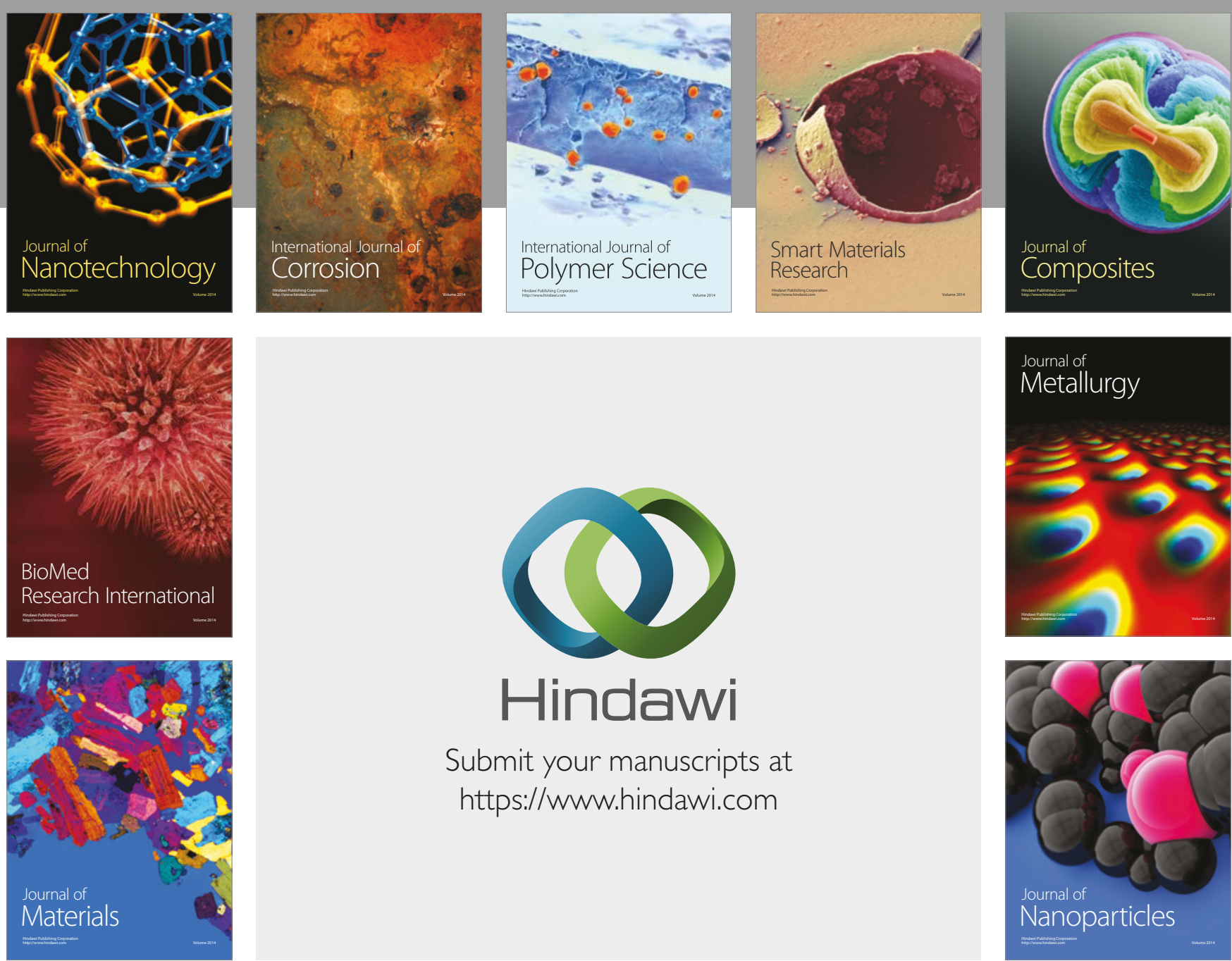

\section{Hindawi}

Submit your manuscripts at

https://www.hindawi.com
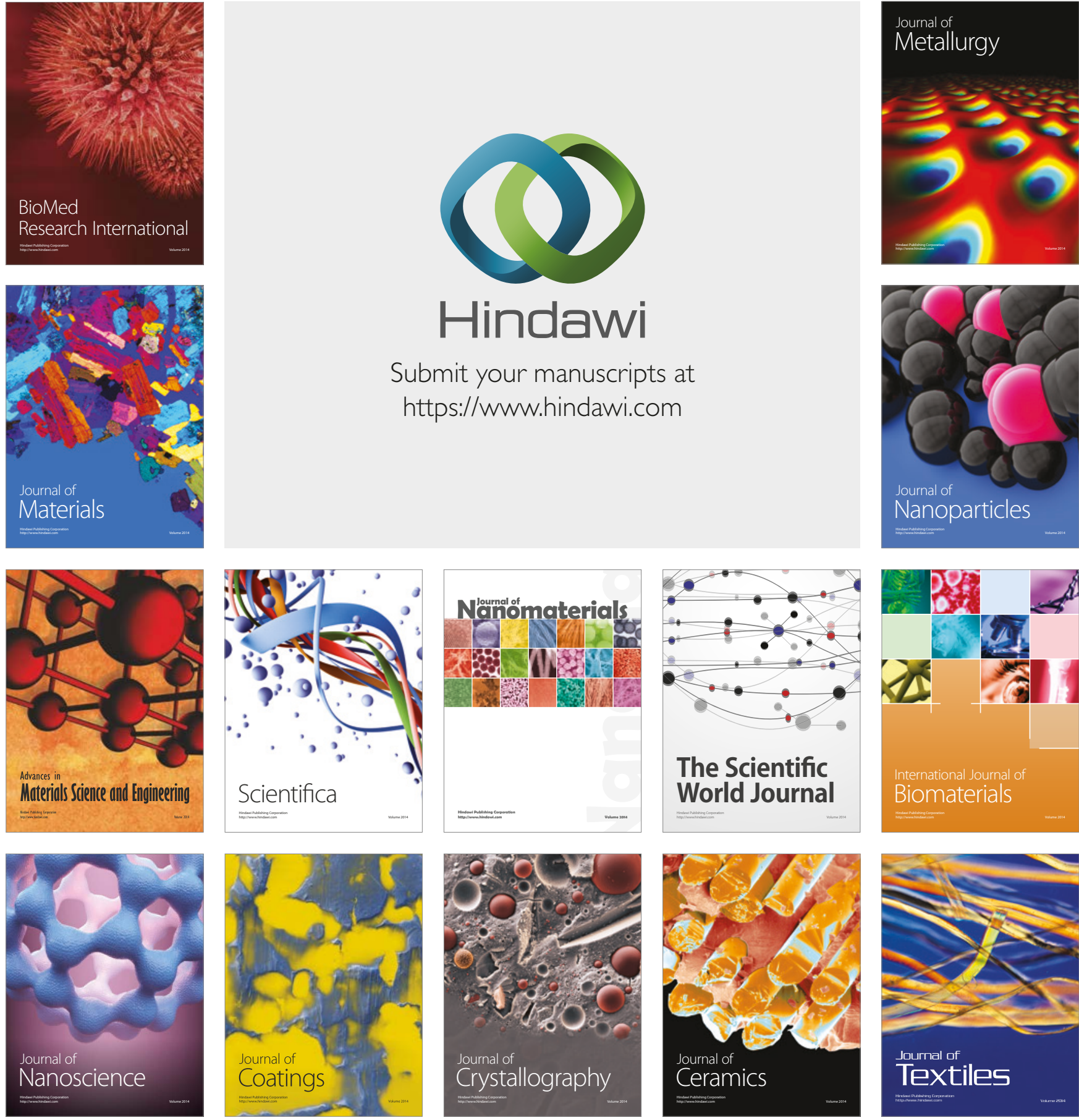

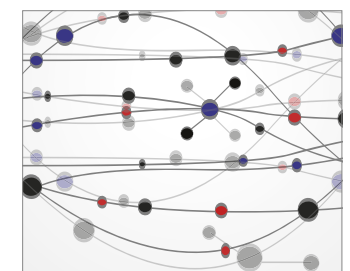

The Scientific World Journal
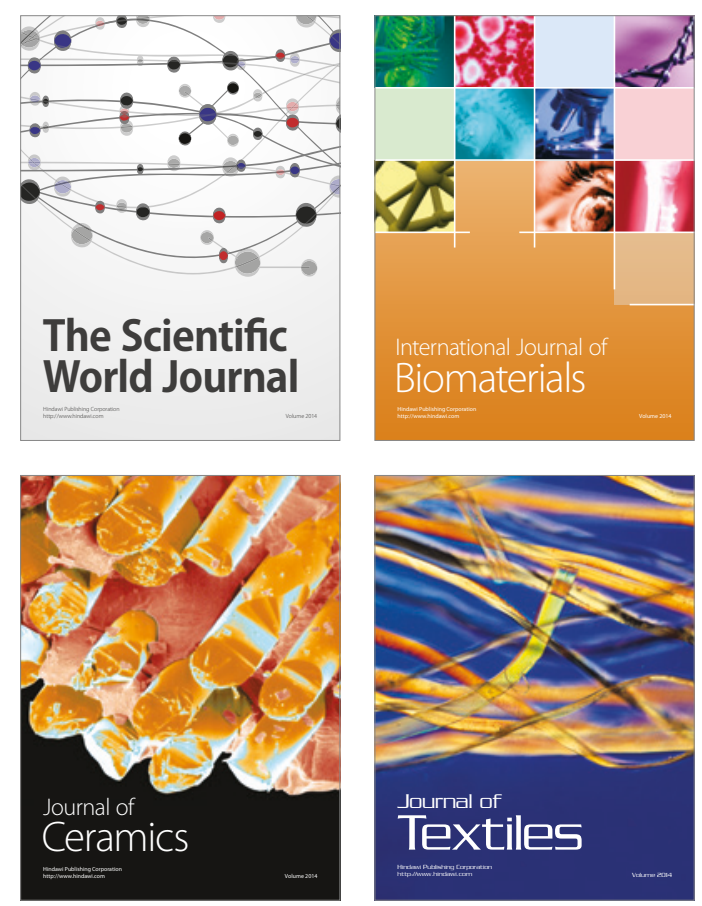